\title{
Availability Estimation for Facilities in Extreme Geographical Locations
}

\author{
Gerd M. Fischer, ManTech International / NASA Goddard Space Flight Center \\ Oluseun Omotoso, Morgan State University \\ Guangming Chen, Morgan State University \\ John W. Evans, NASA Goddard Space Flight Center
}

Key Words: Reliability Block Diagram, Logistic Analysis

\section{SUMMARY \& CONCLUSIONS}

A value added analysis for the Reliability, Availability and Maintainability of McMurdo Ground Station was developed, which will be a useful tool for system managers in sparing, maintenance planning and determining vital performance metrics needed for readiness assessment of the upgrades to the McMurdo System. Output of this study can also be used as inputs and recommendations for the application of Reliability Centered Maintenance (RCM) for the system.

ReliaSoft's BlockSim [1], a commercial Reliability Analysis software package, has been used to model the availability of the system upgrade to the National Aeronautics and Space Administration (NASA) Near Earth Network (NEN) Ground Station at McMurdo Station [2] in the Antarctica. The logistics challenges due to the closure of access to McMurdo Station during the Antarctic winter was modeled using a weighted composite of four Weibull distributions, one of the possible choices for statistical distributions throughout the software program and usually used to account for failure rates of components supplied by different manufacturers. The inaccessibility of the antenna site on a hill outside McMurdo Station throughout one year due to severe weather was modeled with a Weibull distribution for the repair crew availability. The Weibull distribution is based on an analysis of the available weather data for the antenna site for 2007 in combination with the rules for travel restrictions due to severe weather imposed by the administrating agency, the National Science Foundation (NSF). The simulations resulted in an upper bound for the system availability and allowed for identification of components that would improve availability based on a higher on-site spare count than initially planned.

\section{INTRODUCTION}

The National Aeronautics and Space Administration (NASA) operates a network of satellite ground stations, the Near Earth Network (NEN), to provide tracking, communications, and data system services to its satellite customers. Among the various NEN stations many are geographically remote, including the McMurdo Ground Station (MGS) at McMurdo Station, Antarctica. MGS is operated to facilitate scientific data transfers for polar orbiting satellites. The extreme weather conditions at McMurdo Station, the temporary inaccessibility of some of the ground station facilities, and the semi-annual inaccessibility of the McMurdo Station itself for several months of the year, pose an interesting and difficult challenge to logistics and maintenance activities. This paper presents a method and the results of the development of the statistical distributions for local accessibility based on local weather data, and a second distribution for the logistics for spare items that can only be supplied during the Antarctic summer. The effects of these variations on the overall availability for the MGS station are also estimated using an availability model of McMurdo built in a commercial software package. The utility of these methodologies is shown and these techniques can be adapted to availability estimates for other remote locations.

\subsection{McMurdo Ground Station}

The NASA McMurdo Ground Station is located at the US Antarctic McMurdo Station at $-77.84133^{\circ} / 165.6590^{\circ}$ latitude/longitude close to the southern tip of Hut Point Peninsula of Ross Island at the intersection between the Ross Ice Shelf and the Ross Sea. McMurdo Station is managed by the NSF. During the Antarctic summer season from approximately October to March, supplies can be ferried to McMurdo Station by either ice-breaking ships or transport airplanes. Access to McMurdo Station during the Antarctic Winter Season is closed. 


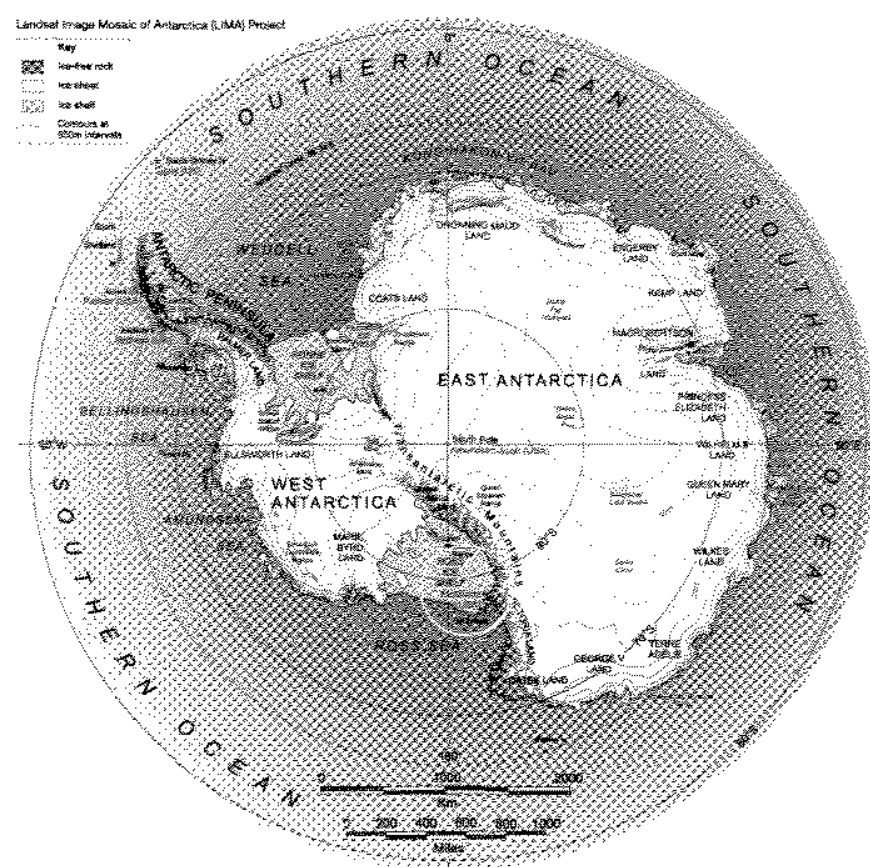

Figure 1: Location of McMurdo Station on the Antarctic Continent.

NASA is operating year round the satellite ground station consisting of Joint System Operations Center (JSOC) in a building in the center of town together with the Transmission Antenna inside a radome (White Dome) with an adjacent support building (Building 71) housing electronic equipment on top of one of the hills about 2 miles from the center of town.

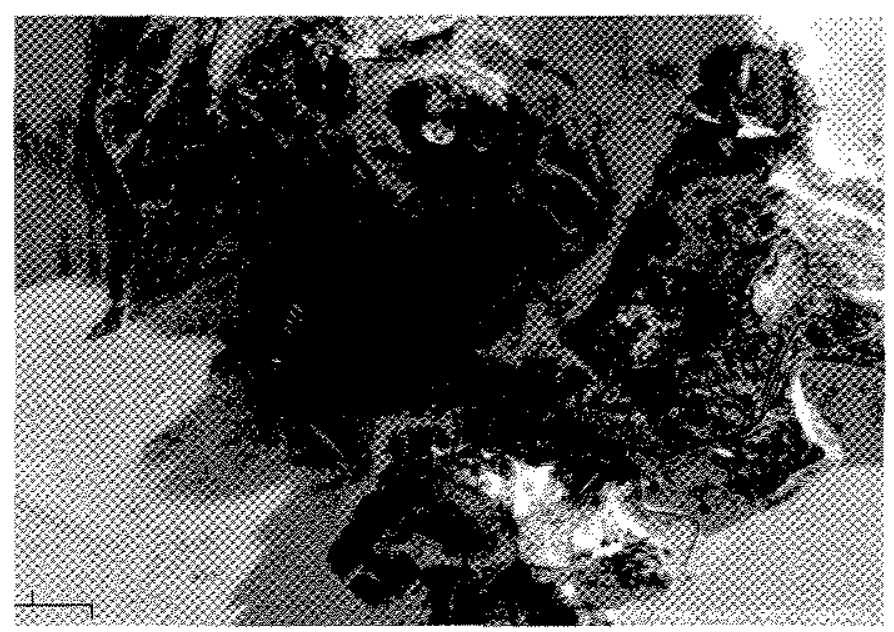

Figure 2: Satellite Image of McMurdo station with NASA MGS Radome on an adjacent hill.

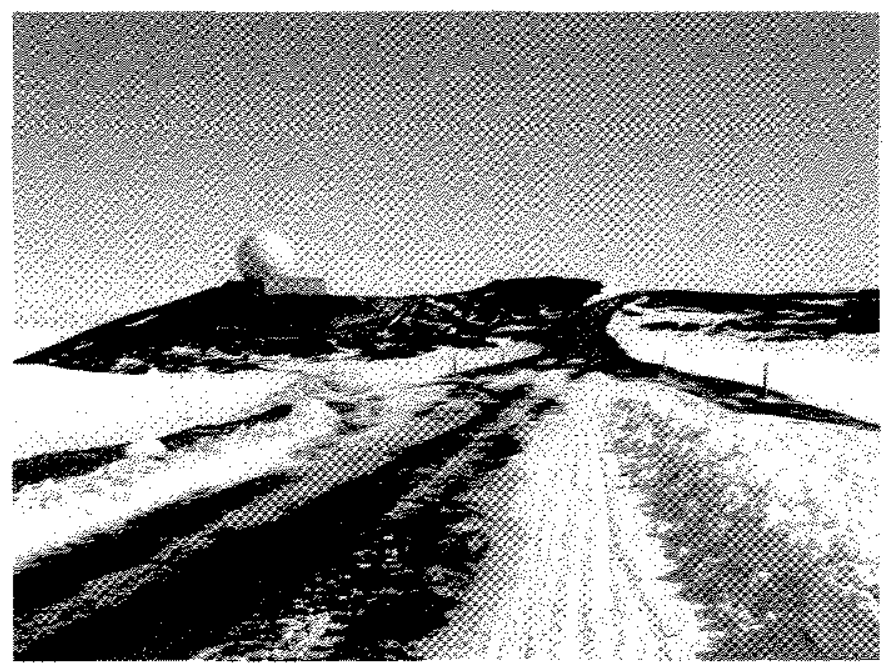

Figure 3: Access road to MGS Radome and Building 71.

\section{SIMULATION TOOLS}

ReliaSoft's BlockSim [1] availability modeling software was used to create a Reliability Block Diagram (RBD) of the McMurdo Ground Station. Throughout the modeling program, the user has the choice between a variety of commonly used statistical distributions (Exponential, Lognormal, etc.) as well as a weighted composite of up to four 2-parameter Weibull distributions for failure rates, repair rates, restocking rates, and repair crew availability rates.

\section{LOGISTICS CHALLENGES}

The extreme geographical location of McMurdo poses two different logistics challenges:

a) During winter closure no spare parts can be supplied to the McMurdo Station. During summer months, any supplies have to be routed through Christchurch, New Zealand.

b) All year round the travel within McMurdo Station as well as to the transmission antenna site might be limited due to weather induced travel restrictions limiting the repair crew availability.

\subsection{Winter Closure of McMurdo Station}

The supply logistics was approximated using the simulation software feature that allows for four weighted 2-parameter Weibull distributions as input to reliability and logistics data.

It was assumed that for about half a year during the Antarctic summer, spare parts can be transported to McMurdo Station by plane within 504 hours (21 days). This scenario was modeled with a Weibull Distribution with a shape parameter $\beta=7$ scale parameter $\eta=480$ hours. Since this scenario is valid for approximately half of the year, it was weighted with 0.49. It was assumed that during Antarctic winter closure, the probability density for the wait time to 
provide spares is constant from 0 hours to $\sim 4380$ hours $\approx$ 6 months Thus, the remaining three Weibull distributions were equally weighted with 0.17 and the shape and scale parameters manually manipulated to achieve a constant probability of an event to fall within the half of the year of winter closure with a roll off beginning at 3500 hours (see Figure 4).

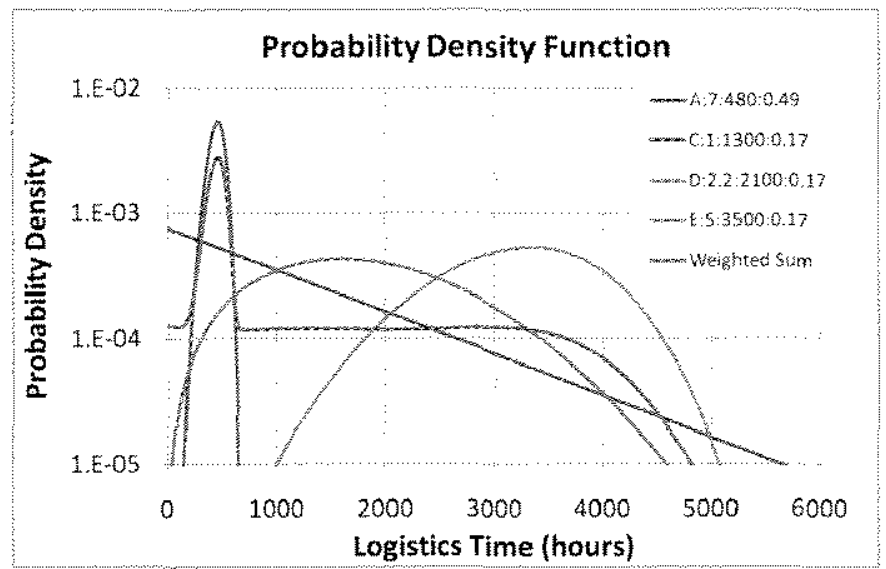

Figure 4: Probability Density Function for the four weighted Weibull distributions and the composite. The legend shows the shape paramenter, the scale parameter and the weight of each distribution.

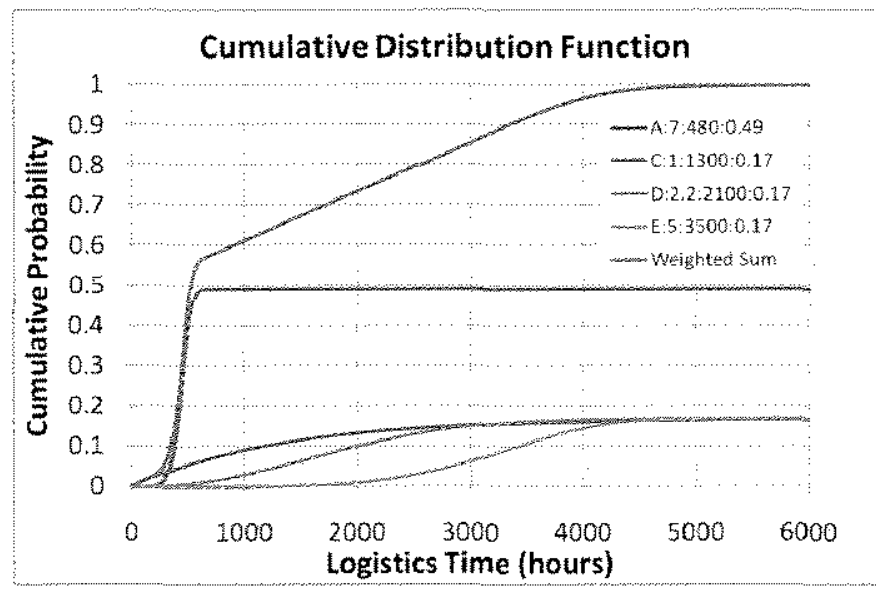

Figure 5: Cumulative Distribution Function for the four weighted Weibull distributions and the composite. The legend shows the shape paramenter, the scale parameter and the weight of each distribution.

The combined weighted cumulative probability distribution reaches $98 \%$ within 6 months or 4380 hours (

\subsection{Local Weather Conditions}

The McMurdo Station Manager is empowered to issue travel restrictions imposed by NSF guidelines for McMurdo Station and adjacent areas.

(Severe) Weather Conditions have historically been instituted to define potential risk situations and allow the establishment of standard procedures to minimize risk. They are issued for McMurdo Station and its immediate vicinity, and are based on observed conditions only.

(Severe) Weather Condition categories are defined as follows:

- Weather Condition THREE:

- Winds $<48$ knots, or

- Wind chill warmer than $-75^{\circ} \mathrm{F}$, or

- Visibility greater or equal to $1 / 4$ statute mile.

- Severe Weather Condition TWO:

- Winds 48 to 55 knots sustained for one minute, or

W Wind chill $-75^{\circ} \mathrm{F}$ to $-100^{\circ} \mathrm{F}$ sustained for one minute, or

- Visibility less than $1 / 4$ statute mile but greater than or equal to 100 feet sustained for one minute.

- Severe Weather Condition ONE:

- Winds greater than 55 knots sustained for one minute, or

- Wind chill colder than $-100^{\circ} \mathrm{F}$ sustained for one minute, or

- Visibility less than 100 feet sustained for one minute.

Condition 3 has no travel restrictions, while during condition 2 , travel is not recommended, and during condition 1 , travel is not allowed.

In addition to the travel restrictions, access to the radome site and Building 71 might be limited due to snow drifts making the access road impassable. Data regarding snow drifts is not recorded, and thus was not available for this analysis. Station Closure Information was only available for part of the $2009 / 2010$ season, and the information only contains time of closure, but not its duration.

Thus, a travel restriction distribution was created based on the weather records. This travel restriction distribution was then used as repair crew availability in the availability analysis.

\subsubsection{Conditions within McMurdo Station town}

Weather conditions for McMurdo Station, which is designated by the acronym NZCM, were avalable for 2002 to 2009 at the website of the Antarctic Meteorological Research Center (AMRC) and Automatic Weather Station (AWS), Space Science Engineering Center, University of Madison, WI [3] -. The stored weather records are only available in two different formats for different periods throughout the years, thus initial analysis was limited to the year 2007 .

\subsubsection{Conditions of access to Antenna Site and Building 71}

For Burlding 71 with the designation NZDT, weather data were available from 2002 to 2009 from the AMRC and AWS website [4] at. Again, most of thears yata was stored in two different- formats for different periods of the year, 
complicating the analysis. Only for most of 2007 , data was stored in the same format, as a text file for each day of the year with a record for each minute.

\subsection{McMurdo / Building 71 weather data analysis}

With the lesser impact of severe weather conditions on moving inside town $n_{\gamma}$ compared to travel up to the Radome, together with the fact that the JSOC at McMurdo Station is being manned by operations personnel (which coufd repair a failed item in some cases of a weather conditio (1) the travel restriction analysis and weather analysis was limited to the Radome / Building 71.

A data sheet was assembled containing the time stamp, wind velocity and wind gust velocity in knots and miles per hour (mph), ambient pressure in mbar, and inside and outside temperature in ${ }^{\circ} \mathrm{F}$ and ${ }^{\circ} \mathrm{C}$. Wind Chill was calculated using

$$
\text { Wind Chill }=35.74+0.6215 \mathrm{~T}+35.75 \mathrm{~V}^{0.16}+0.4275 \mathrm{TV} \mathrm{V}^{0.16}
$$

where $\mathrm{T}=$ temperature in Formula in ${ }^{\circ} \mathrm{F}, \mathrm{V}=$ wind velocity in $\mathrm{mph}$, and the resulting Wind Chill is in ${ }^{\circ} \mathrm{F}$.

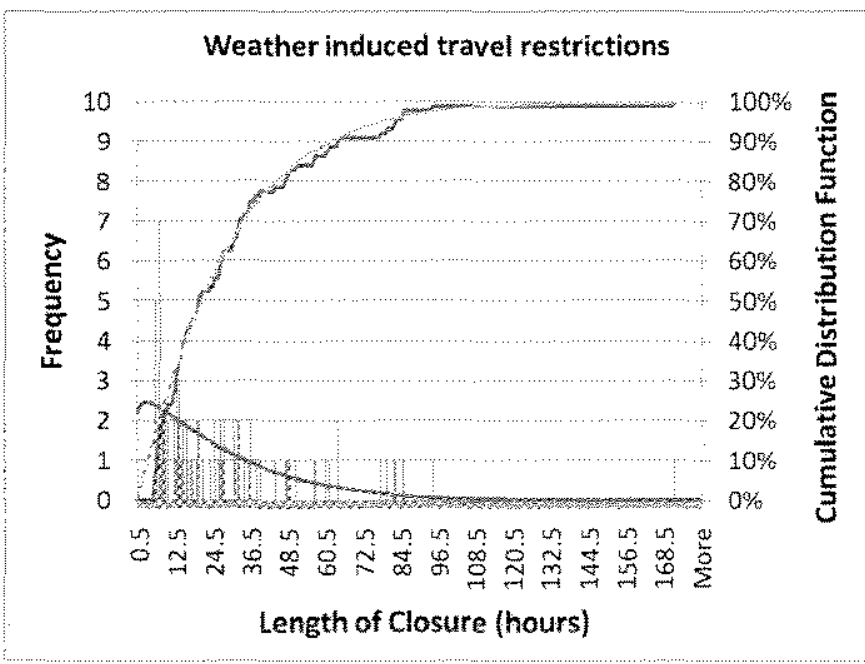

Figure 6: Histogram of weather induced travel restriction to Radome and Building 71 due to weather conditions 1 and 2 with approximated probability distribution (red) (left axis). The Cumulative Distribution Function with approximation is also shown (right axis).

The wind velocity and the wind chill data for each data entry were evaluated for their impact on the weather condition. Visibility data was not available and thus not taken into account. Weather condition 2 or 1 in either field, wind chill or wind velocity was assumed to result in an inaccessibility of the Radome for the following six hours. During an arctic winter storm, this could result in continuous travel restrictions for several days. All closure events would then be binned and a cumulative closure distribution created, as shown in Figure 6. The Cumulative Distribution Function for the weather induced travel restrictions was manually approximated with a Weibull Distribution with a shape parameter $\beta=1.25$ and a scale parameter $\eta=30$ hours. This distribution was used as crew availability for repairs at the Radome and in Building 71.

\subsection{Availability Analysis based on BlockSim}

A Reliability Block Diagram was created from the system architecture diagram provided by the Implementation Contractor and the Operations and Maintenance Contractor. Failure rates were supplied by the Operations and Maintenance Contractor as well as the Implementation Contractor. The failure and repair distributions were assumed to be exponential. The failure rates were based on MILHDBK-217 [6], field data of identical or similar items or engineering estimates. The repair times were based on engineering estimates. The on-site sparing was retrieved from the initial sparing plan. The weighted 4 factor Weibull distribution was used for the restock probability distribution for McMurdo Ground Station equipment, the repair crew availability at Building 71 was modeled with the Weibull Distribution based on the weather induced travel restrictions. For the availability simulations, Preventive Maintenance as well as electrical power outages were not taken into account. The system was modeled for the design life of 10 years $=$ 87600 hours.

\section{RESULTS}

Based on the above mentioned assumptions, the mean availability of the McMurdo Ground Station system was $89 \%$ for the 10 year design life.

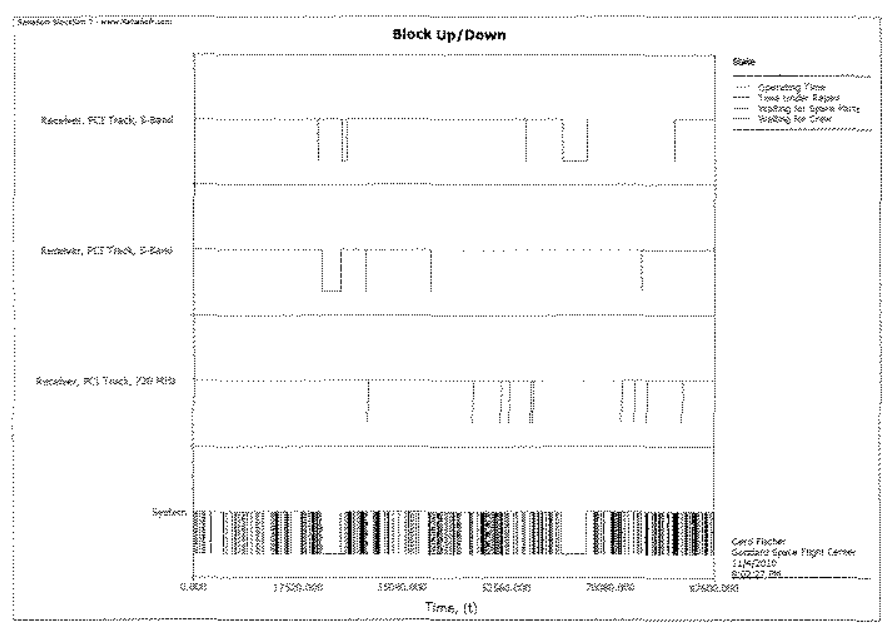

Figure 7: Up/down time of tracking receivers for MGS during 10 year life for a single trial of the Monte Carlo simulation. Both $\mathrm{S}$ - band tracking receivers are required, thus each leading to system downtime (bottom track).

The Reliasoft BlockSim outputs contain the Block Failure Criticality list and the Block Downtime Ranking list. The Block Failure Criticality list sorts the blocks used in the model 
according to their percentage causing a system failure, and the Block Downtime Ranking according to the percentage of the system downtime the block causes. While the first one is a good measure of the reliability of the system blocks, the latter one is a measure for the system unavailability due to a specific block's failure.

\section{Table 1: Block Failure Criticality Summary}

\begin{tabular}{|c|c|}
\hline \multicolumn{2}{|l|}{ Block Fatlure Criticality Summary } \\
\hline Slock Name (Diagram) & RS ECR \\
\hline Receiver, PCI Track, S-Band $\{22000$ Multichannel Autotrack Receiver $\}$ & $2.40 \%$ \\
\hline Receiver, PCI Track, $720 \mathrm{MHz}\{22000$ Multichannel Autotrack Receiver $\}$ & $2.39 \%$ \\
\hline Receiver, PCI Track, S-Band $\{22000$ Muttichannel Autotrack Receiver $\}$ & $2.37 \%$ \\
\hline
\end{tabular}

Table 2shows the first three entries of the Block Failure Criticality Summary. The PCI Tracking Receivers for both SBand polarizations and the X-Band Tracking Receiver had the lowest reliability in the system each causing approximately $2.4 \%$ of all system failures.

Table 2 shows block downtime ranking. During the 10 year life of the system, each of the S-Band Tracking Receivers with around 900 hours block downtime is responsible for about $10 \%$ of the total system downtime, and the X-Band tracking receiver with about 600 hours for about $7 \%$. The

Table 2: Block Downtime Ranking

\begin{tabular}{|c|c|c|}
\hline \multicolumn{3}{|c|}{ Block Downtime Ranking } \\
\hline Slock Name (Diagram) & $\begin{array}{c}\text { stock } \\
\text { Downtime }\end{array}$ & $\begin{array}{l}\text { Contribution to } \\
\text { Downtime if not in } \\
\text { redundant } \\
\text { configuration }\end{array}$ \\
\hline $\begin{array}{c}\text { Receiver, PCI Track, S-Band } \\
\{22000 \text { Multichannel Autotrack Receiver }\} \\
\text { Receiver, } \mathrm{PCl} \text { Track, S-Band } \\
\{22000 \text { Multichannel Autotrack Receiver }\} \\
\text { Receiver, } \mathrm{PCI} \text { Track, } 720 \mathrm{MHz} \\
\{22000 \text { Muttichannel Autotrack Receiver }\}\end{array}$ & $\begin{array}{l}904.9772 \\
880.8062 \\
622.4443\end{array}$ & $\begin{array}{l}9.85 \% \\
9.59 \% \\
6.78 \%\end{array}$ \\
\hline
\end{tabular}

initial sparing plan included one S-Band Tracking receiver spare and one X-Band tracking receiver spare at McMurdo Station.

Figure 7 shows an example of one run of the MontemCarlo simulation for the system downtime due to outage of the SBand PCl Tracking Receivers required for the two polarizations of the signal and the X-Band $\mathrm{PCl}$ Tracking Receiver. During the 10 year life, major downtime is incurred when both $S$-Band receivers fail in short succession (first outage) or when one receiver and subsequently the replacement spare fail (second outage). As can be seen in this trial, there can be long periods of up to two years without any failure in the S-Band tracking receivers. Also in this run, the $X-B$ and tracking receiver does not contribute to major downtime of the system.

An updated sparing plan with additional spares is being considered which increases the simulated availability to about $96 \%$, a $7 \%$ percent increase.

\section{ACKNOWLEDGMENTS}

We are grateful for the support by the NASA NEN Systems Manager, Kevin McCarthy, and the Operations and Maintenance Contractor Personnel, David Hess and Bonnie Kramer.

\section{REFERENCES}

1. http/wwweliasoftcom/Blocksm/index.hm

2. http://esc.gsfe.nasa.gov/space-communications/NEN.htm1

3. ftp/amressec.wisc.edu/pub/aws/spawar/2007/

4. ftp/amrc.ssec.wisc edu/pub/ncmurdobulding 71

5. http/www nws noaa gov/om/windchll

6. Military Handbook, Reliability Prediction of Electronic Equipment, US Department of Defense 


\title{
Availability Estimation for Facilities in Extreme Geographical Locations
}

\author{
Gerd M. Fischer, Ph.D. \\ ManTech International / NASA Goddard Space Flight Center
}

Oluseun Omotoso, Morgan State University

Guangming Chen, Morgan State University

John W. Evans, NASA Goddard Space Flight Center

RAMS 2012

January 23-26, Reno, Nevada 


\section{Outline}

- Project Objectives

- McMurdo Ground Station

- Seasonal accessibility of McMurdo Station

- Travel restriction at McMurdo Station due to weather

- Availability Simulation Results

- Summary 


\section{Project Objectives}

- Develop a value added analysis for the Reliability and Maintainability at McMurdo Sound

- Analysis of availability

- Benefits: Affect sparing and maintenance planning for upgrades to the McMurdo System

- Recommendations for RCM implementation

- Benefits: Affect cost effective preventive maintenance and predictive maintenance to ensure availability 


\section{Location}

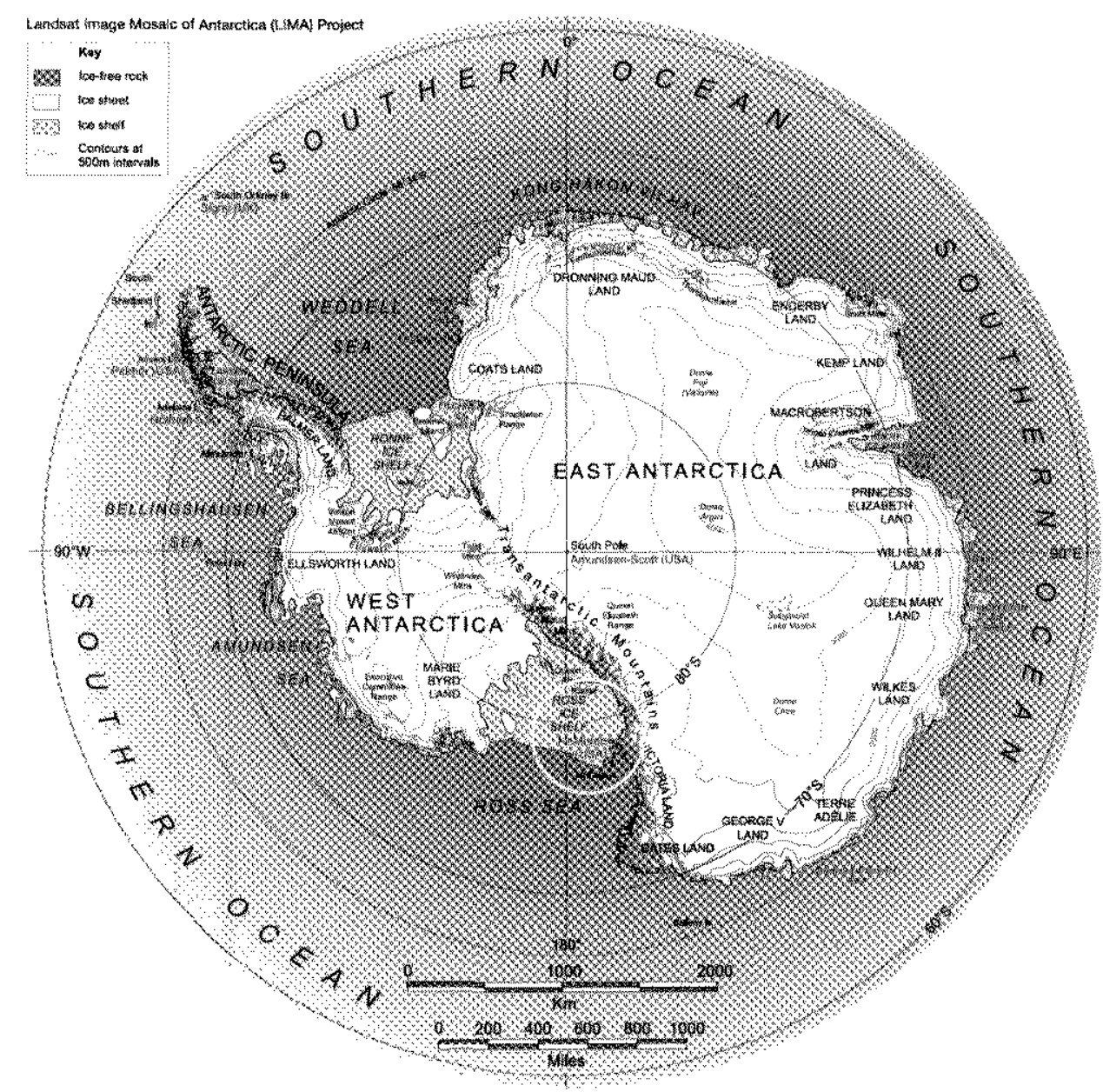




\section{McMurdo Station - Radome and JSOC}

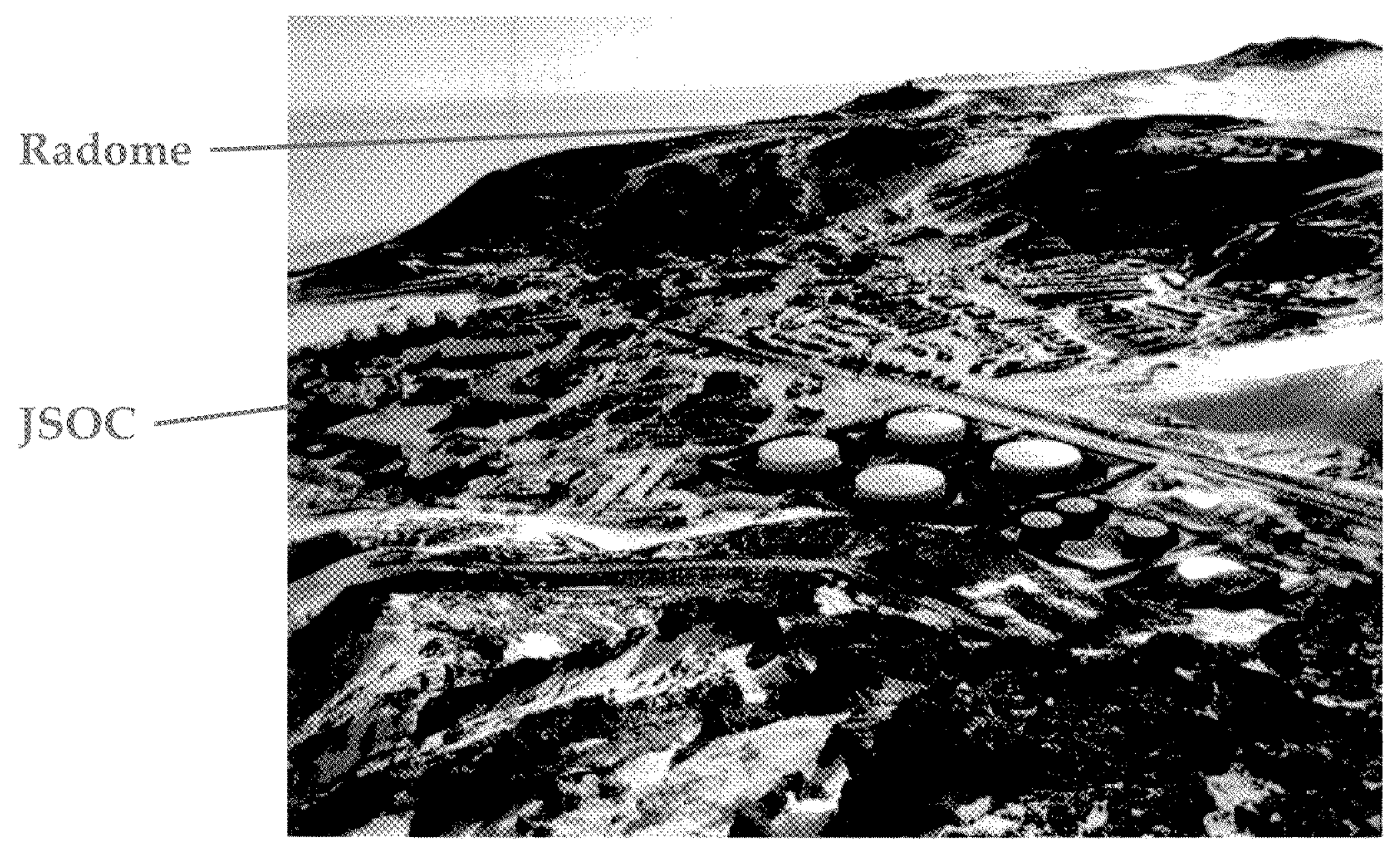




\section{Availability Analysis}

- System Model in ReliaSoft BlockSim

- Consider special conditions for extreme location 


\section{Special Conditions for McMurdo Station}

1. No possibility to re-stock spares during Antarctic winter from April to November / Logistics

Will be taken into account in simulation with statistical distribution for re-stock probability

2. Limited access of Building 71 / Radome due to travel restrictions based on (severe) weather conditions

- Winds

- Wind Chill (temperature)

- Visibility (no information available)

- Road closure due to wind drift (no information available)

$>$ Will be taken into account in simulation in repair crew availability 


\section{Logistics Distribution for restock due to winter closure}

- $50 \%$ of the spare parts during 6 summer months are provided within 500 hours (21 days)

- During winter closure constant probability density of wait time to provide spares ( 0 hours to $\sim 4380$ hours $\approx 6$ months) 


\section{Logistics Distribution for restock due to winter closure}

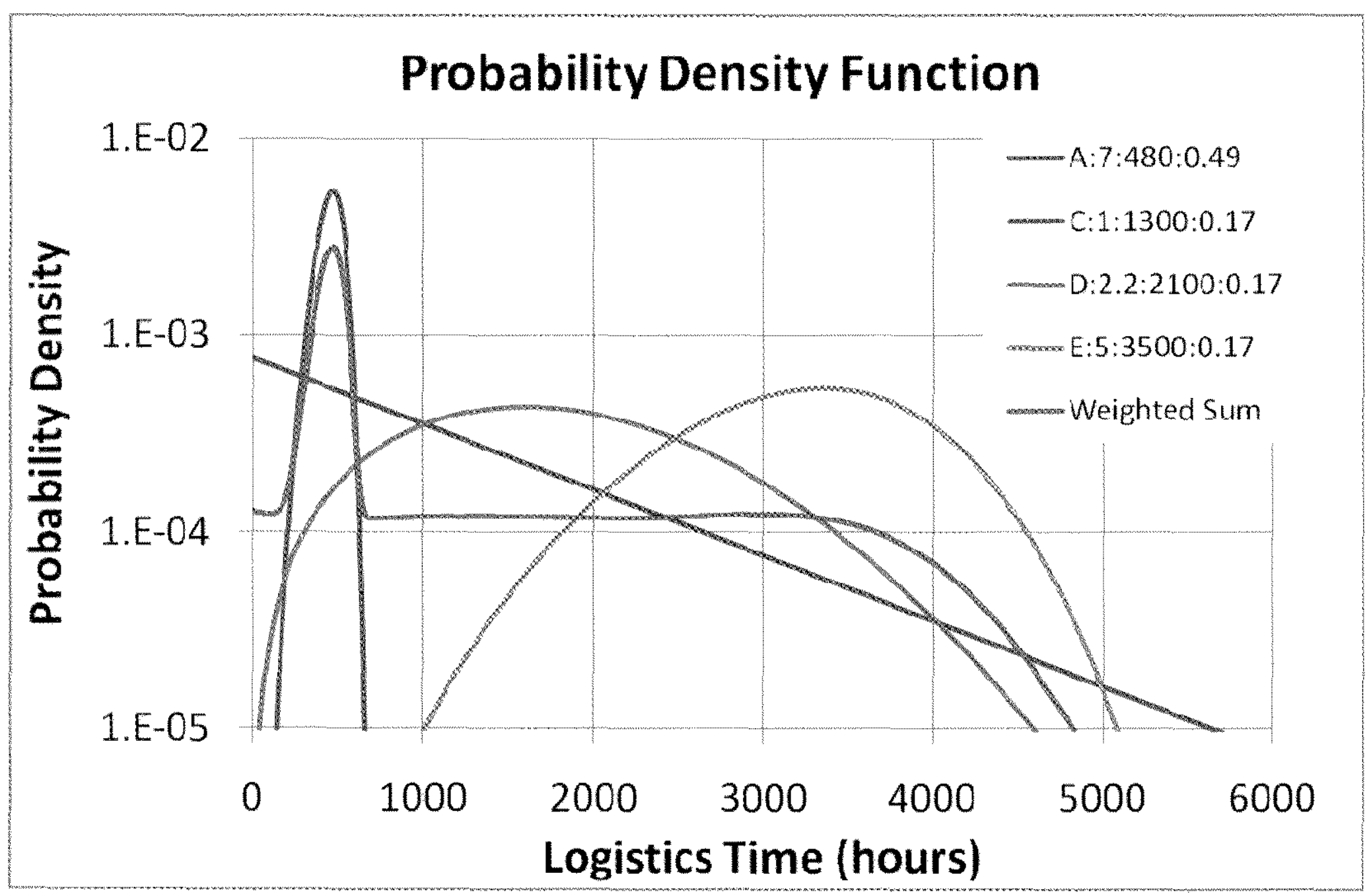




\section{Logistics Distribution for restock due to winter closure}

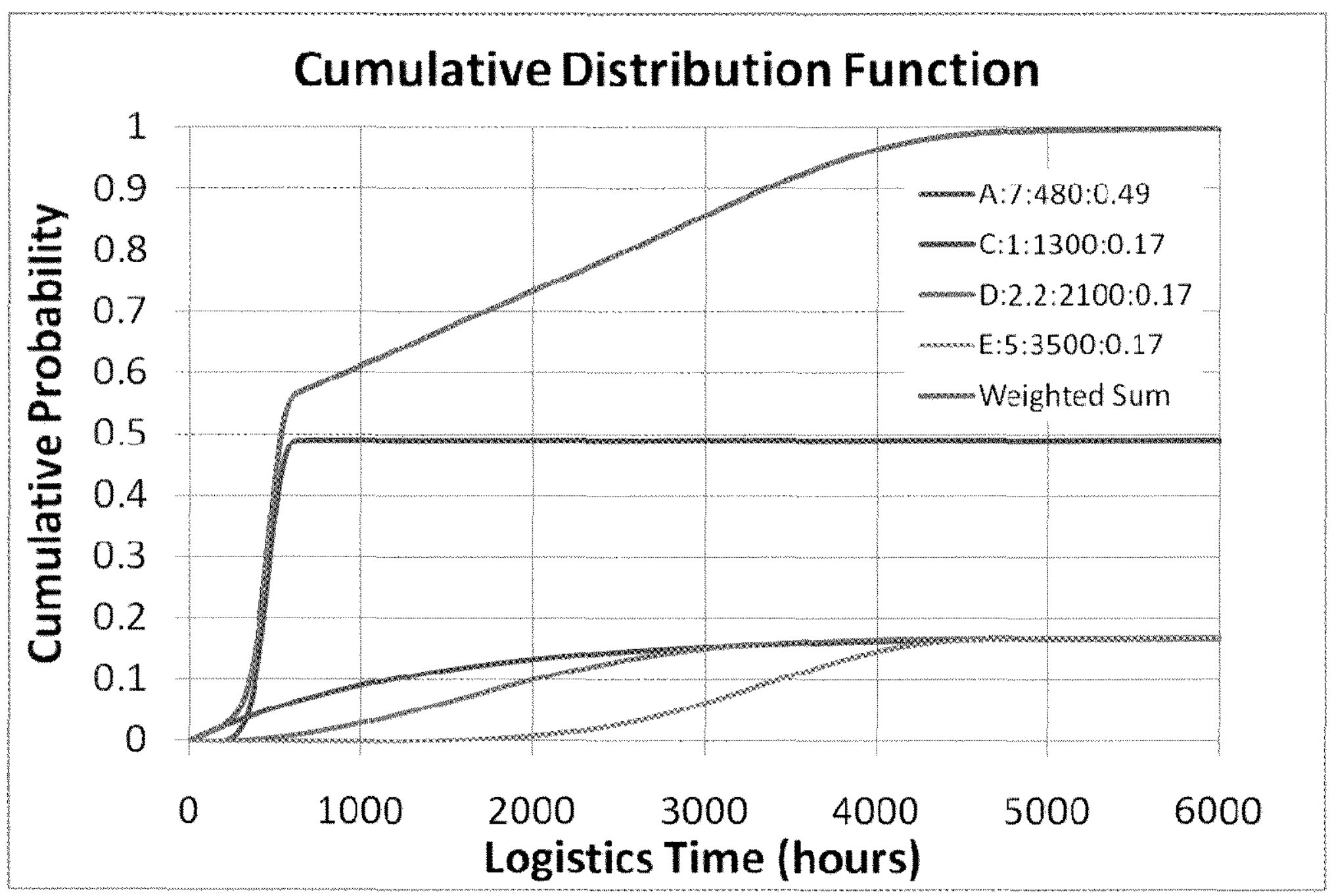




\section{Weather Conditions / Travel Advisory}

- (SEVERE) WEATHER CONDITIONS

- (Severe) Weather Conditions have historically been instituted to define potential risk situations and allow the establishment of standard procedures to minimize risk. They are issued for McMurdo Station and its immediate vicinity, and are observed conditions only.

- (Severe) Weather Conditions are set for the following locations:

- McMurdo Station;

- T-Site;

- Arrival Heights;

- Scott Base Road;

- Scott Base;

- Ice Runway;

- Ice Road to Ice Runway;

- Williams Field;

- Pegasus;

- Ice Road from Ice Runway to Williams Field; and

- Snow Road. 


\section{Weather Conditions}

- Travel restrictions imposed by NSF for weather condition 1 or 2 . Condition 3 has no travel restrictions.

- (Severe) Weather Condition categories are defined as follows:

- Weather Condition THREE:

- Winds $<48$ knots, or

- Wind chill warmer than $-75^{\circ} \mathrm{F}$, or

- Visibility greater or equal to $1 / 4$ statute mile.

- Severe Weather Condition TWO:

- Winds 48 to 55 knots sustained for one minute, or

- Wind chill $-75^{\circ} \mathrm{F}$ to $-100^{\circ} \mathrm{F}$ sustained for one minute, or

- Visibility less than $1 / 4$ statute mile but greater than or equal to 100 feet sustained for one minute.

- Severe Weather Condition ONE:

- Winds greater than 55 knots sustained for one minute, or

- Wind chill colder than $-100^{\circ} \mathrm{F}$ sustained for one minute, or

- Visibility less than 100 feet sustained for one minute. 


\section{Calculation of Weather Conditions}

- Only weather conditions of Radome/Building 71 site taken into account

- Sustained wind speed and wind gust speed data available from Antarctic Meteorological Research Center (AMRC) and Automatic Weather Station (AWS), Space Science Engineering Center, University of Madison, WI

- Calculated Wind Chill according to NOAA/NWS issued index:

Wind Chill $=35.74+0.6215 \mathrm{~T}+35.75 \mathrm{~V}^{0.16}+0.4275 \mathrm{TV}^{0.16}$

$\mathrm{T}\left({ }^{\circ} \mathrm{F}\right) ; \mathrm{V}(\mathrm{mph}) ;$ Wind Chill $\left({ }^{\circ} \mathrm{F}\right)$

- Determined travel restrictions due to severe weather (wind and wind chill)

- Assumes a minimum closure time of 6 hours

- Added 0.5 hours offset to Closure duration (travel time to Building 71)

- Created Histogram for weather induced travel restrictions

- Approximated with 2-parameter Weibull distribution 


\section{Determination of Travel Restrictions}

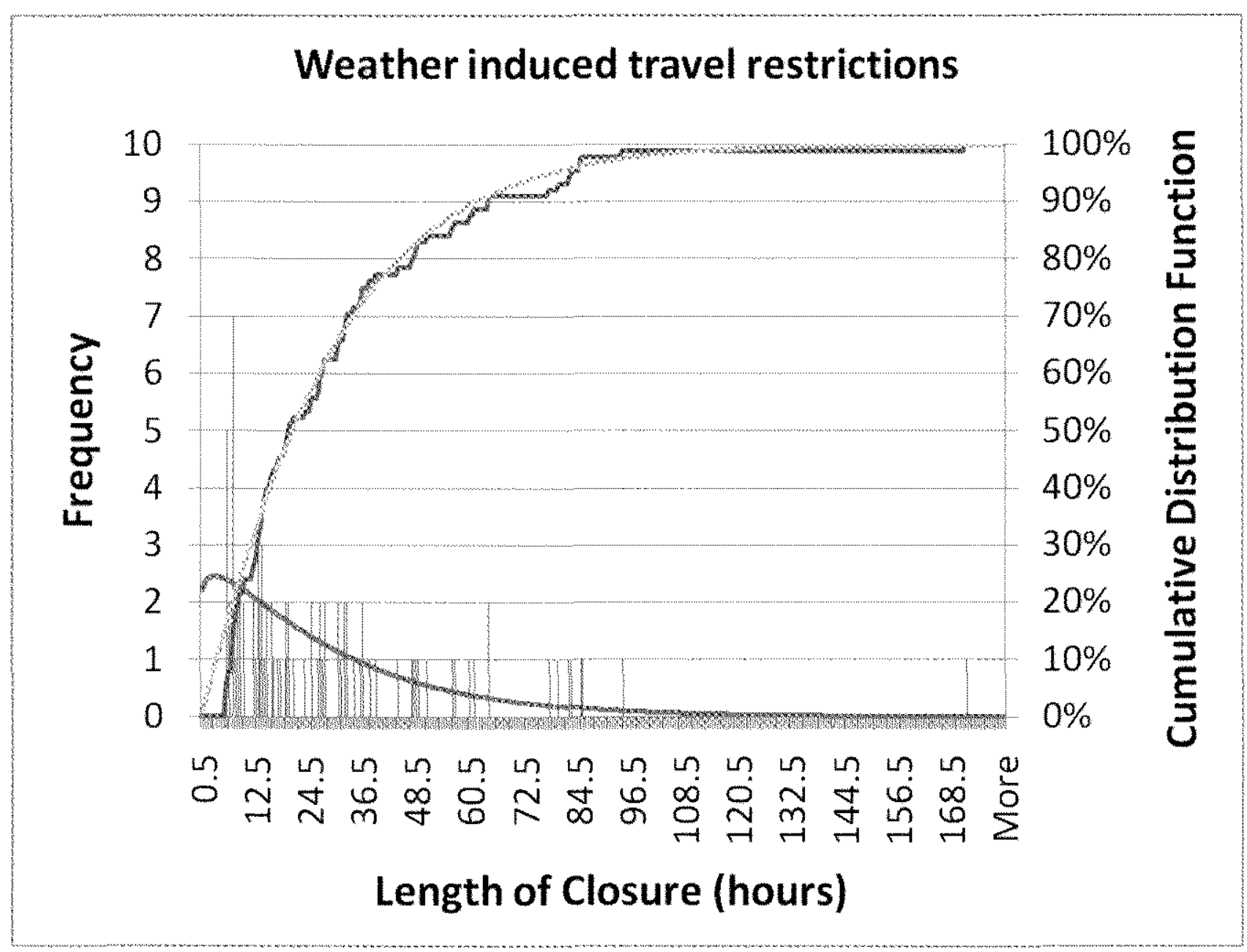

- Repair Crew Availability for Building 71 and Radome modeled with Weibull Distribution with beta $=1.25$ and eta $=30$ 


\section{Availability Analysis - Assumptions}

- Reliability Block Diagram created from architecture diagram provided by Operations and Maintenance Contractor and Implementation Contractor

- Exponential failure and repair distribution assumed

- MTBF data based on

- MIL-HDBK-217

- Field data of similar items

- Engineering Estimates 


\section{Availability Analysis - Assumptions (cont.)}

- Crew availability for JSOC and Wallops Flight Facility instantaneous

- Crew availability for Radome / Building 71 modeled with Weibull distribution (beta $=1.25$, eta $=30$ hours)

- Restock Logistics modeled with sum of 4 weighted Weibull distributions

- Power failure of McMurdo Station not taken into account

- No preventive maintenance assumed

- Assumed Life of 10 years $=87600$ hours 


\section{System Summary}

\begin{tabular}{|r|c|}
\hline \multicolumn{3}{|c|}{ System Overview } \\
\hline General & \\
Mean Availability (All Events): & 0.8951 \\
Std Deviation (Mean Availability): & 0.0611 \\
Mean Availability (w/O PM \& Inspection): & 0.8951 \\
Point Availability (All Events) at 87600: & 0.8937 \\
Reliability(87600): & 0 \\
Expected Number of Failures: & 249.5587 \\
Std Deviation (Number of Failures): & 21.2275 \\
MTTFF: & 312.9974 \\
& \\
System Uptime/Downtime Uptime: & 78412.271 \\
CM Downtime: & 9187.7295 \\
Inspection Downtime: & 0 \\
PM Downtime: & 0 \\
Total Downtime: & 9187.7295 \\
& \\
System Downing Events & 249.5587 \\
Number of Failures: & 249.5587 \\
Number of CMs: & 0 \\
Number of Inspections: & 0 \\
Number of PMs: & 249.5587 \\
Total Events: &
\end{tabular}




\section{Block Failure Criticality}

does not take redundancy into account

\begin{tabular}{|c|c|}
\hline \multicolumn{2}{|l|}{ Block Failure Criticality Summary } \\
\hline Block Name (Diagram) & RS FCI \\
\hline Receiver, PCI Track, S-Band \{22000_Multichannel Autotrack Receiver\} & $2.40 \%$ \\
\hline Receiver, PCI Track, 720 MHz \{22000_Multichannel Autotrack Receiver $\}$ & $2.39 \%$ \\
\hline Receiver, PCI Track, S-Band \{22000_Multichannel Autotrack Receiver\} & $2.37 \%$ \\
\hline
\end{tabular}




\section{Block Downtime Ranking \\ does not take redundancy into account}

\begin{tabular}{|c|c|c|}
\hline \multicolumn{2}{|c|}{ Block Downtime Ranking } \\
\hline Block Name (Diagram) & $\begin{array}{c}\text { Block } \\
\text { Downtime } \\
\text { Downtime if not in } \\
\text { redundant } \\
\text { configuration }\end{array}$ \\
\hline $\begin{array}{c}\text { Receiver, PCI Track, S-Band } \\
\{22000 \text { Multichannel Autotrack Receiver\} }\end{array}$ & 904.9772 & $9.85 \%$ \\
$\begin{array}{c}\text { Receiver, PCI Track, S-Band } \\
\text { \{22000_Multichannel Autotrack Receiver\} } \\
\text { Receiver, PCI Track, 720 MHz }\end{array}$ & 880.8062 & $9.59 \%$ \\
$\{22000$ Multichannel Autotrack Receiver\} & 622.4443 & $6.78 \%$ \\
\hline
\end{tabular}




\section{Block Downtime}

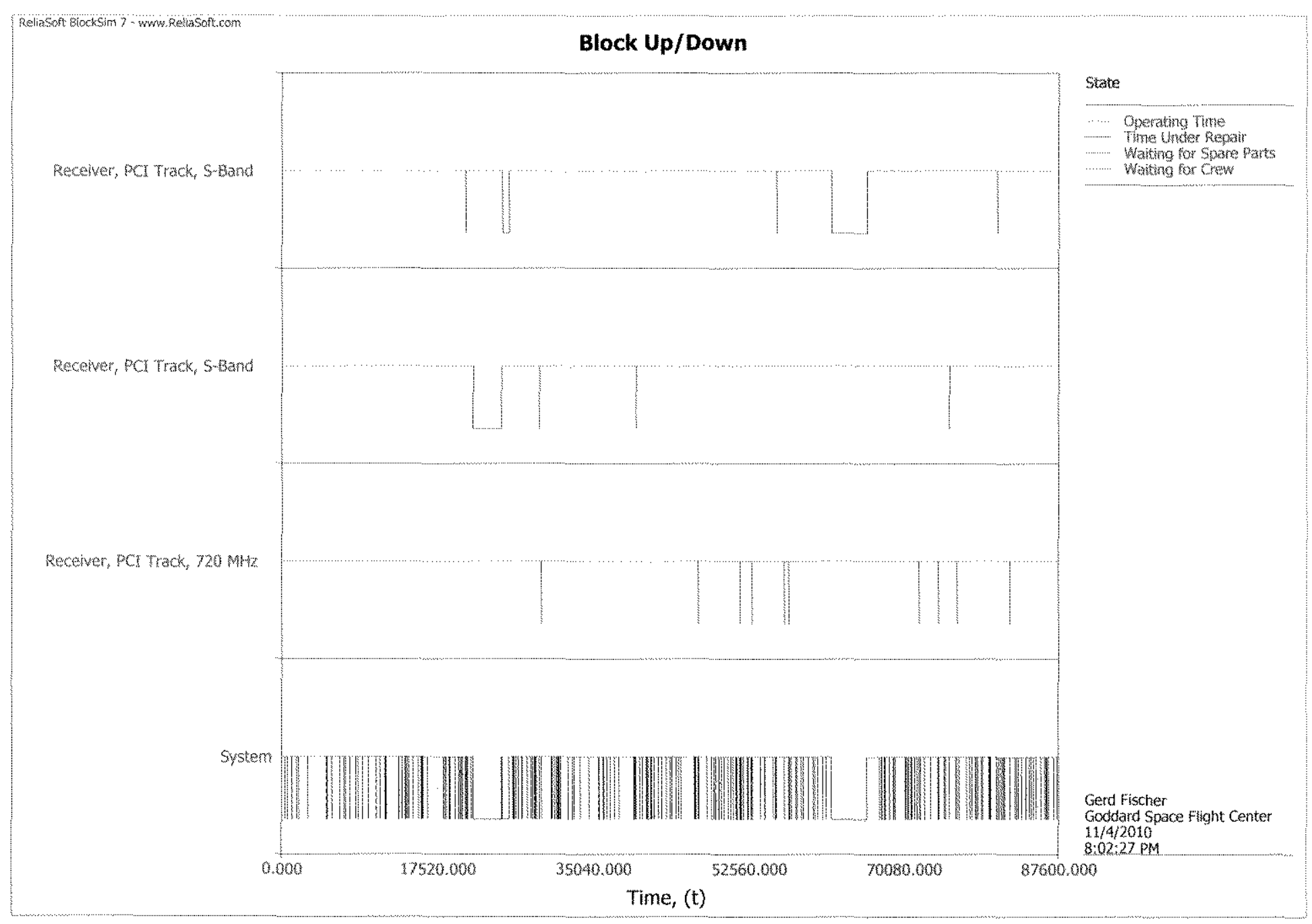

RAMS 2012, January 23.26, Reno, Nevada 


\section{Summary}

- Performed Availability Analysis for McMurdo Ground Station System

- The extreme geographical location of McMurdo poses two different logistics challenges:

- During winter closure no spare parts can be supplied to the McMurdo Station. During summer months, any supplies have to be routed through Christchurch, New Zealand.

Modeled with sum of 4 weighted Weibull Distributions for restocking spares

- All year round the travel within McMurdo Station as well as to the transmission antenna site might be limited due to weather induced travel restrictions limiting the repair crew availability.

Analyzed weather data for McMurdo and estimated weather induced travel restrictions to antenna site

Modeled with Weibull Distribution for crew availability at antenna site

- Provided Downtime Ranking to update sparing plan 


\section{Acknowledgement}

- Thanks to

- NASA NEN Systems Manager Kevin McCarthy

- GN QAEs Bill Dusterwald and Larry Hartnett

- MG1 System Engineers David Hess and Bonnie Kramer 